\title{
Attitudes toward Immigration: The Role of Personal Predispositions
}

Peter Thisted Dinesen (ptd@sam.sdu.dk)

Robert Klemmensen (rkl@sam.sdu.dk)

Asbjørn Sonne Nørgaard (ano@sam.sdu.dk)

Department of Political Science, University of Southern Denmark

Paper prepared for the 4th Annual NYU-CESS Experimental Political Science Conference, March 4-5 2011

\begin{abstract}
In this paper we examine how individual predispositions in terms of the Big Five personality traits affect attitudes toward immigration. This allows us go beyond the assumption that individuals react to situational factors in a uniform way, which underlies established theories of attitudes toward immigration focusing mainly on economic and cultural threat. Adding personality traits to the explanation of attitudes toward immigration allows us to develop a more full understanding of attitude formation beyond situational factors as well as more insight into how individuals react differently based on their personality when confronted with the same situational triggers. We examined the question of how personality influence attitudes toward immigration using a Danish survey experiment and show that personality traits display direct as well as conditional effects on opposition towards immigration. As expected, we find that that Openness and Agreeableness have strong effects on attitudes toward immigration; individuals scoring high on these two traits are significantly more willing to admit immigrants compared to individuals scoring lower on the traits. We also find evidence that individuals react differently to economic threat depending on their score on the trait Conscientiousness; individuals scoring high on Conscientiousness have a greater tendency to oppose low-skilled immigration than individual scoring lower on this trait. This result implies that the influence of situational factors may critically depend on personality traits. More generally, the results suggest that the literature on political attitude formation may benefit from including more differentiated models of man.
\end{abstract}




\section{Introduction}

Research has focused on two explanations of attitudes toward immigration: economic threat, centered around material interest in terms of economic well-being, and cultural threat, focusing on the concern for a distinctive social and cultural identity (Sides \& Citrin, 2007; Sniderman et al., 2004). While the explanatory mechanism differs between the two perspectives, they implicitly assume that individuals respond uniformly when disposed to the same situational trigger in terms of economic or cultural threat. However, recent research suggests individuals think and behave differently politically according to their personal predispositions in terms of their personality, thereby making this assumption of uniformity untenable (Carney et al., 2008; Gerber et al., 2010; Jost et al., 2009; Mondak \& Halperin, 2008; Mondak et al., 2010a). Building on these insights we examine how personality - in terms of the so-called Big Five personality dimensions - influence attitudes toward immigration beyond that of economic and cultural threat, but also in conjunction with these situational factors. We thereby contribute to both the literature about the formation of attitudes toward immigration as well as the burgeoning literature on the influence of personality traits on political attitudes and behaviors.

We examine the question about the impact of personality on attitudes toward immigration using a Danish survey, which include the 60-item NEO-FFI inventory measuring the five personality traits included in the Big Five personality scheme: Openness to experience, Conscientiousness, Extraversion, Agreeableness, and Neuroticism. This represents an improvement over most previous studies (e.g. Mondak et al., 2010a; Gerber et al, 2010), which have relied on a reduced, ten-item personality inventory that measures the traits less reliably (Gosling et al., 2003). In the survey, we embedded a survey experiment in which we varied economic and cultural threat, thereby enabling us to analyze whether the influence of personality traits on attitudes toward immigration are uniform across the two most important situational factors or contingent upon these factors.

In the following we discuss how different personality traits may influence attitudes toward immigration. We focus on the Big Five personality scheme (cf. Costa \& McRae, 1992; Goldberg, 1992, 1993; McRae \& Costa, 1999), which is by now the dominant model of personality within in trait theory (John et al., 2008). In the next section we present our research design, data and operationalizations of the variables employed in the analyses. Then we present the results of the empirical analysis before concluding by discussing our findings. 


\section{Personality and attitudes toward immigrations}

Contrary to traditional approaches to political attitude formation within political science, recent research has emphasized how stable psychological predispositions also influence the political attitudes that people hold (Gerber et al., 2010; Mondak \& Halperin, 2008; Mondak et al., 2010a). Personality psychologists have reached a working consensus that personality traits can be conceptualized and reliably measured by the following five general orientations or trait dimensions known as the Big Five: Openness (to Experience), Conscientiousness, Extraversion, Agreeableness, Neuroticism (or its inverse, Emotional Stability) (Costa \& McRae, 1992; Goldberg, 1992, 1993; McRae \& Costa, 1999). People who are high on Openness to Experience tend to be open-minded, tolerant, creative, curious, and generally appreciate encounters with novel and alternative ideas, people and situations. Scoring high on Conscientious implies a strong impulse control, dutifulness, and sense of organization, as well an adherence to norms and rules, and a preference for order and dependability. Extraversion is associated with an energetic, active and excitement-seeking approach to life, outgoing and sociable behavior, and positive emotionality in general. Individuals scoring high on Agreeableness are typically characterized by being co-operative, sympathetic, altruistic, modest and generally pro-social and communal in their orientation toward other people. A high score on Neuroticism is associated with anxiety, uneasiness, feelings of vulnerability and a high sensitivity to negative emotions in general. The five personality traits are influenced by genetic differences and childhood experiences and become stable early in life (Bouchard and McGue, 2003). Therefore, traits are only to a very limited extent susceptible to socially induced changes later in life and as such it makes sense to see these traits as exogenous to various political attitudes and behaviors including attitudes toward immigration that we study in this paper.

Previous studies have shown that the Big Five personality traits exercise an important influence on political attitudes more generally (Gosling et al., 2003; Mondak and Halperin, 2008; Carney et al., 2008; Jost et al., 2009; Gerber et al., 2010; Mondak et al., 2010a; cf. also McRae \& Costa, 1999), but no previous studies have looked at the impact of the Big Five personality traits on attitudes toward immigration. That said, the study of the role personality in forming attitudes toward immigration and prejudice more generally is by no means a new phenomenon. Dating back to the work of Adorno et al. (1951) and Allport (1954) with subsequent extensions by Pratto, Sidanius, Stallworth, \& Malle (1994) (Social Dominance Orientation) and Altemeyer (1981) (Right-Wing Authoritarianism), there is an important line 
of work emphasizing the role of the so-called authoritarian personality in forming prejudice towards out-groups in general. However, as pointed out by Sibley \& Duckitt (2008) in a recent review, authoritarianism and related phenomena, have been criticized for not referring to generalized dispositions, but rather express basic social attitudes and values. Instead, authoritarianism is in itself influenced by more fundamental underlying personality traits and as such mediates the influence of personality on prejudice (Duckitt, 2001; Duckitt et al., 2002; Ekehammar et al., 2004). For that reason we focus on the role of the five personality dimensions in the Big Five personality scheme rather than more proximate values or attitudes. In that regard, the literature provides some directions to the potential role of the Big Five personality traits in forming attitudes toward immigration. The results show that particularly Openness, and to a lesser extent Agreeableness and Conscientiousness, are related to ethnic or racial prejudice - either directly or indirectly through more proximate factors - (Flynn, 2005; Sibley \& Duckitt, 2008) and therefore we have the strongest expectations about the role of these traits in explaining attitudes toward immigration.

We conjecture that people, who are high on Openness to Experience, with their tolerance for diversity, appreciation of novelty, and positive response to unconventional and complex stimuli, will be positive toward immigration. Moreover, given their tendency to actively pursue new information - even when it challenges existing ideas and beliefs - individuals high on Openness are more subject to change their opinion according to stereo-typedisconfirming information regarding minority group members (Flynn, 2005; Gerber et al., 2010). Conversely, people low on Openness cherishes unambiguous moral prescripts and rules describing how the world should operate. Consequently, they are likely to be more sensitive to threats to the existing social order including outgroups "which espouse values different from their own" (Sibley \& Duckitt, 2008: p. 252).

We expect individuals high on Agreeableness to hold pro-immigration attitudes as their altruistic, trusting and pro-social orientations toward other people in general should also embody a tolerance towards newcomers and therefore less strict immigration attitudes. Conversely, people low on Agreeableness, who view the world with less eye to the wellbeing of others and society as a whole, would tend to be more skeptic toward immigration, which they are likely to see as an influx of potential competitors for scarce resources (Sibley \& Duckitt, 2008). 
People high on Conscientious with their strong preference for order and dependability may fear that increased immigration will work to undermine the existing social order - either because immigrants threaten the viability of the welfare state or because they do not comply with social and cultural norms of the host society - and for that reason they are likely oppose immigration. Highly conscientious people, with their strong sense of duty, may feel obliged to prevent this from happening by opposing immigration. While no direct evidence exists specifically for attitudes toward immigration, Gerber et al. (2010) showed that Conscientiousness is positively correlated with conservative political attitudes in general and specifically with regard to the social domain to which attitudes to immigration are likely to be counted.

There is less evidence that the two last traits in the Big Five scheme, Neuroticism and Extraversion, play a role in forming general prejudice. Consequently we have less strong expectations regarding their impact on attitudes toward immigration. One may expect the uneasy and anxious nature of people scoring high on Neuroticism would result in negative attitudes toward immigration as immigrants may be seen as a disturbing and potentially threatening factor among emotionally unstable people. Extroversion influences the more social aspects of politics including political activism and participation, but it is less obvious how it would be related to attitudes toward immigration. However, we included both these traits in order to explore the collective impact of the Big Five scheme.

Above we have focused on how we expect the five personality traits in the Big Five scheme directly impact attitudes toward immigration. However, in addition to examining the direct impact, we also scrutinize the indirect impact of personality on attitudes toward immigration, which is in line with the work by Gerber et al. (2010) and Mondak et al. (2010a). They show that the impact of personality on political attitudes and behavior is often contingent on various situational (contextual) factors. As mentioned earlier, economic and cultural threat are the main situational factors influencing attitudes toward immigration identified in the literature. For that reason, we include these two factors in the analysis of the impact of the five personality traits on attitudes toward immigration in order to examine the extent to which the impact of personality extends beyond that of the main situational factors. However, we also examine whether the impact of personality is contingent on the two situational factors as we analyze how the impact of the five personality traits is conditioned by economic and cultural threat. That is, we ask whether individuals with certain personality characteristics are more or less prone to respond negatively to economic and/or cultural threat. This part of the 
analysis is mainly explorative and for that reason we do not explicit state hypotheses about how the five personality traits are conditioned by the two situational factors.

\section{Research design, data and variables}

Like many other countries, Denmark - the context studied in this paper - has experienced massive immigration in the last part of the $20^{\text {th }}$ century. Politically, the issue of immigration has become a very salient issue on the political agenda from the early 90's onwards embodied in the growing popularity of the populist right-wing party the Danish Peoples Party, which has anti-immigration as an important aspect of their political platform.

In studying the question of the importance of personality in forming attitudes toward immigration in the Danish context, we build on a nationally representative sample of the Danish population in terms of a web-survey. The survey was distributed to a representative sample of an Internet panel containing approximately 400.000 Danes. It was fielded between May $25^{\text {th }}$ and June $6^{\text {th }} 2010$. Invitations to participate in the survey were sent to 8012 persons and 3612 answered the questionnaire, which equals a response rate of 45 per cent.

As mentioned earlier, the dependent variable of the study was measured through a surveyexperiment in which respondents were asked about whether "Denmark should allow more high-/low-skilled immigrants from Western/non-Western countries to move here". As the freedom of movement is widespread within the EU, we specified in the introduction to the question that the respondents should only focus on immigrants coming from outside the EU and Europe. Subjects were randomly assigned to four vignettes/frames differentiating between the various combinations of the two conditions in the survey experiment: skill level (high- and low-skilled) and country of origin (Western and non-Western) of immigrants. ${ }^{1}$ By using this design we are able to distinguish between concerns relating to the two main explanations of anti-immigration attitudes: economic concerns (related to the skill level of immigrants) and cultural concerns (related to the culture of the country of origin). The

\footnotetext{
${ }^{1}$ A fifth neutral vignette asking whether "Denmark should allow more immigrants to move here" was also included in the survey, but we decided to exclude this vignette from the analyses as it rendered contrast between the two conditions in the survey experiment less clear and tended to obfuscate the impact of personality across the conditions. This also accounts for most of the drop in number of observations in the analyses compared to the number of respondents having answered the survey (the rest is due to non-response on various variables).
} 
response options to the question in the survey experiment were "Strongly agree" (1), "Agree somewhat" (2), "Disagree somewhat" (3), "Strongly disagree" (4) and "Don’t know" (5). We excluded the latter from the analysis. In table 1 we show the wording of the four vignettes/frames as well as the distribution of the answers to each question. ${ }^{2}$

[Table 1 about here]

Table 1 shows that the most positive attitudes are expressed toward high-skilled Western immigrants, closely followed by high-skilled non-Western immigrants. Conversely, the greatest opposition towards immigration is expressed towards low-skilled non-Western immigrants and low-skilled Western immigrants for which the opposition is virtually identical. This suggests that skill level (i.e. economic considerations) rather than country of origin (i.e. culture) is what discriminates in attitudes toward immigration in Denmark.

Measuring the big five personality traits we rely on a 60-item inventory (Neo-FFI) (cf. John et al., 2008), which holds 12 items related to each of the five personality dimensions. The 60item inventory provides a more reliable measure compared to the ten-item instrument (TIPI) (Gosling et al. 2003) used in much previous research focusing on the impact of the big five personality traits on political attitudes (e.g., Mondak et al., 2010a; Gerber et al, 2010). At the same time, by using the 60 item inventory instead of the full 240 item inventory (Neo-PI-R) (Costa \& McRae, 1992), we strike a balance between obtaining a reliable personality measure without wearying respondents down, which is likely to happen if the latter is used in a survey like ours with a large number of other questions. The personality assessment consists of 60 statements about the respondents to which the respondent was asked to indicate their agreement on a five point Likert scale with the categories "Strongly agree", "Agree somewhat", "Neutral", "Disagree somewhat" and "Strongly disagree". In constructing a scale for each of the five personality dimensions we summated the 12 statements (identically signed) relating to a given dimension. Generally speaking, the response distribution on the statements in the inventory was not markedly skewed and for that reason we did not - as has been done in some work (Mondak, 2010) - log the items before constructing the scales, which were close to normally distributed. All scales were constructed to range between 0

\footnotetext{
${ }^{2}$ In all analyses we employed a sampling weight in order to make the sample nationally representative.
} 
(lowest observed value on the trait) to 1 (highest observed value on trait). Table 2 shows the descriptive statistics for the scales constructed for each of the five personality traits and the alpha value for each of the scale. The alpha values range from 0.716 for Openness to 0.848 for Neuroticism, thereby showing that the constructed scale are internally consistent.

[Table 2 about here]

In the models estimating the determinants of attitudes toward immigration we include the socio-demographic variables of gender and age as well the standard SES variables of education (captured through three dummies with having completed primary school as the reference category) and household income (measured on a scale from 0 to 10 ). In order to show the extent to which personality traits influence attitudes toward immigration beyond the traditional SES predictors, we run analyses with and without education and income as well as personality. In line with Mondak et al. (2010b), we leave out attitudinal and dispositional variables, which research has shown is influenced by personality traits (Gerber et al., 2010) and therefore would tend to obscure the relationship between personality traits and attitudes toward immigration.

\section{Results}

The results of the empirical analyses are reported in Table 3 and 4. Table 3 is explorative and reports the results for four separate models for each combination of the two conditions (skills and country of origin) separately. However, we cannot infer from these separate models whether the impact of the personality traits are significant across conditions nor whether they vary significantly across conditions. This is tested in Table 4, which displays models in which the four frames are collapsed into one dependent variable with dummies indicating each condition included as independent variable. That is, dummies indicating whether the respondent responded to the high-/low-skilled frame, the Western/non-western frame and an interaction between the two frames in order to examine whether special premiums are attached to certain combination of the two conditions. In both tables, we estimate three models: a model including only the five personality traits, a model including only education 
and household income, and a model including both the personality traits and the SES variables. Comparing the three models enables us to assess the extent to which five personality traits exert an impact on attitudes toward immigration beyond that of the SES predictors. All models were estimated using ordered probit regression due to the rank-ordered nature of the dependent variable. In the analyses, the dependent variable was reversed so higher values indicate more positive attitudes toward immigration.

[Table 3 about here]

[Table 4 about here]

The results in Table 3 and 4 strongly support that personality affects attitudes toward immigration. Importantly, the impact of personality holds up after controlling for education, household income, age, and gender. This clearly indicates that attitudes toward immigration are rooted in deep-held personality structures and not only subject to more external factors such as economic concerns or educational attainment. Looking at the specific personality traits, we find many of the expected patterns. The personality dimensions of Openness, Agreeableness and Conscientiousness are significantly related to attitudes toward immigration, while this is not the case for the last two traits, Extraversion and Neuroticism, for which we did not have strong expectations.

Openness has a highly significant impact on attitudes toward migration and as expected, people scoring higher on Openness, who are characterized by tolerance and openmindedness, generally tend to be significantly more pro-immigration. Moreover, the impact of Openness is universal in the sense that it is independent of the immigrant group in question. In other words, being high on Openness generally entails a more positive attitude towards immigrants regardless of their cultural or educational background. While it is well known that Openness is correlated with education, it is important to note that the positive impact of Openness remains highly significant after controlling for education and, hence, that this trait exerts an influence on attitudes toward immigration independent of the level of education. To the extent that personality traits can be considered mostly exogenous to 
education this can be interpreted as people scoring higher on openness self-selecting into higher education. More generally, this finding has important implications for earlier research looking at the impact of education on attitudes toward immigration, as the observed effect is likely to be upwardly biased due to people scoring higher on openness self-selecting into higher education.

While not as markedly as Openness, Agreeableness also exerts a significant influence on attitudes toward immigration, as persons higher on agreeableness tend to view immigration more positively. This is in accordance with our expectation given that people high on Agreeableness tend to be characterized by altruism, tender-mindedness and trust, which are all features we expected to be positively related to pro-immigration attitudes. Equivalent to that of Openness, the positive impact of agreeableness on attitudes toward immigration is universal in the sense that the impact of Agreeableness is not statistically different for different groups of immigrants.

The uniform impact of Openness and Agreeableness stands in contrast to the impact of Conscientiousness for which we find a conditional negative impact on pro-immigrant attitudes. Conscientiousness only has a negative impact on attitudes toward low-skilled immigration, which is shown in Table 3 and tested more formally in column five in Table 4 through an interaction between high-skilled immigration and Conscientiousness. To give a more intuitive presentation of this finding, we have illustrated the contingent relationship between Conscientiousness and attitudes toward immigration in Figure 1 in which we have plotted the predicted probability of strongly agreeing or agreeing that more immigrants should be allowed to immigrate into Denmark depending on the skill-level of the group as well as the level of conscientiousness of the respondent (varying from 0 to 1 ). The predicted probabilities are plotted for Western immigrants for a respondent with mean values on the four other personality traits, household income and age and mode values on gender (man) and education (vocational education).

[Figure 1 about here]

Figure 1 clearly shows how the impact of Conscientiousness on attitudes toward immigration is dependent on the skill-level of the immigrants in question. There are no differences in 
attitudes toward high-skilled immigration according to the respondents' level of Conscientiousness as high-skilled immigration is strongly supported independent of the score on this personality trait. Conversely, for low-skilled immigration, the respondents' score on Conscientiousness differentiates markedly in attitudes toward immigration. Among highly Conscientiousness individuals, the predicted probability of supporting increased low-skilled immigration is a mere 0.14 , while the equivalent predicted probability for respondents with low levels of Conscientiousness is 0.58 amounting to a marked difference in predicted probabilities of 0.44 . In other words, the respondents' attitudes toward immigrants with varying skill-levels are highly contingent on their personal predispositions in terms of their score on the personality trait of Conscientiousness. Given the emphasis attached to order and reliability by people scoring high on Conscientiousness, we believe that the negative impact of this trait on attitudes toward low-skilled immigrants may reflect that people scoring high on Conscientiousness are likely to see this group as threat to the welfare state. Individuals scoring high on Conscientiousness, who are characterized by strong impulse control and laboriousness themselves, may tend to think that non-skilled immigrants do not hold such qualities, and for that reason less likely to become integrated into the labor market thereby incurring cost on the welfare state of the host society. Consequently, highly conscientious people, with their strong sense of duty, may see it as their obligation to prevent this from happening by opposing low-skilled immigration. More generally, the conditional impact of Conscientiousness on attitudes toward immigration points to the interplay between dispositional and situational factors discussed in recent work on the role of personality in forming political attitudes and behavior.

While not the main of the paper, the results of the analyses also provide some evidence on the situational factors and hence the traditional explanations on the determinants of attitudes toward immigration. Looking at household income and age, the results for both variables are in line with the economic threat explanation emphasizing economic self-interest perspective. Household income has a modest positive impact on attitudes toward immigration, which may reflect that the economically privileged feel less vulnerable to the potential negative effects of immigration. Age has an overall negative impact on attitudes toward immigration, but as shown in Table 3 , this effect is in fact contingent on the type of immigration in question as older respondents react negative only to low-skilled immigration (interaction term significant at $\mathrm{p}>0.01$, results not shown). A likely interpretation of this effect is that older respondents are exclusively opposed to low-skilled migrants, whom they consider to be contestant for 
scarce resources from the welfare state in terms of pensions and health care services etc. Looking at the effect of education, opposition to immigration drops markedly with the level of education, although the effect of education is non-linear as having completed high school seems to be the threshold for having the least restrictive attitudes toward migration with no added effect from completing a college/bachelor's degree. This may reflect that the economic situation people with higher education are less vulnerable to immigration and as such support the economic self-interest perspective. ${ }^{3}$ However, it may also be seen as evidence in favor of more sociologically inspired theories emphasizing how completing higher levels of education breed less restrictive attitudes toward immigration by reducing prejudice (Gaasholt \& Togeby, 1995; McClosky \& Brill, 1983; Schuman, Bobo \& Steeh, 1985). Finally, the cultural perspective also receives some support. While there is no premium attached to immigration from the more culturally similar Western countries in general, which is evident from the dummy tapping immigrants coming from Western countries being insignificant, there is a special premium attached to coming from a Western country for high-skilled immigrants, as witnessed by the significant two-way interaction term in Model 4. In other words, highskilled Western immigrants are the group for which the most positive attitudes exist and this may reflect that this group is generally thought to be more easily integrated into the destination society due to holding culture and customs closer to that of native citizens.

\section{Conclusion}

In the present paper we have examined how individual predispositions in terms of the Big Five personality traits affect attitudes toward immigration. This is important because it allows us go beyond the assumption that individuals react to situational factors in a uniform way, which underlie established theories of attitudes toward immigration focusing on economic and cultural threat. Hence, adding personality traits allows us to develop a more full understanding of attitude formation beyond situational factors as well as more insight into

\footnotetext{
${ }^{3}$ In line with the work by Hainmueller \& Hiscox (2010) we also examined the labour market competition thesis, which states that opposition toward high and low-skilled immigration is contingent on the skill level of the respondent with opposition being strongest towards immigrants with skill-levels similar to the respondent's own as this group are the potential competitors for jobs. In accordance with the findings by Hainmueller \& Hiscox (2010) in the United States, we find little support for the labor competition thesis as including interaction effects between immigrant skill level (high vs. low-skilled) and the respondents' skill level (education) to Model 3 in Table 4 showed no significant effects.
} 
how individuals react differently based on their personality when confronted with the same situational triggers. We examined the question of how personality influence attitudes toward immigration using a Danish survey experiment and show that personality traits display direct as well as conditional effects on opposition towards immigration. As expected, we find that that Openness and Agreeableness have strong effects on attitudes toward immigration; individuals scoring high on these two traits are significantly more willing to admit immigrants compared to individuals scoring lower on the traits. We also find evidence that individuals react differently to economic threat depending on their score on the trait Conscientiousness; individuals scoring high on Conscientiousness have a greater tendency to oppose low-skilled immigration than individual scoring lower on this trait. Collectively, the results suggest that the literature on political attitude formation may benefit from including more differentiated models of man by incorporating explanations emphasizing individual predispositions in terms of personality. 


\section{References}

Adorno, T. W., Frenkel-Brunswick, E., Levinson, D. J. \& Sanford, N. S. (1950). The Authoritarian Personality. New York: Harper.

Allport, G. W. (1954). The Nature of Prejudice. Cambridge MA: Addison-Wesley

Altemeyer, R. A. (1996). The Authoritarian Specter. Cambridge MA: Harvard University Press.

Bouchard, T. J., Jr., \& McGue, M. (2003). Genetic and environmental influences on human psychological differences. Journal of Neurobiology, 54: 4-45

Carney, D. R., Jost, J. T., Gosling, S. D. \& Potter, J. (2008). The Secret Lives of Liberals and Conservatives: Personality Profiles, Interaction Styles, and the Things They Leave Behind. Political Psychology, 29: 807-40.

Costa, P. T., and McCrae, R. R. (1992). NEOPI-R. Professional Manual. Odessa, FL: Psychological Assessment Resources.

Duckitt, J. (2001). A dual-process cognitive-motivational theory of ideology and prejudice. In Zanna, M.P. (Ed.), Advances in Experimental Social Psychology, 33: 41-113. San Diego: Academic Press.

Duckitt, J., Wagner, C., de Plessis, I. \& Birum, I. (2002). The psychological bases of ideology and prejudice: Testing a dual-process model. Journal of Personality and Social Psychology, 83: 75-93.

Ekehammar, B., Akrami, N., Gylje, M., \& Zakrisson, I. (2004). What matters most to prejudice: Big-Five personality, Social Dominance Orientation, or Right-Wing Authoritarianism? European Journal of Personality, 18, 463-482.

Flynn, F. J. (2005). Having an open mind: The impact of openness to experience on interracial attitudes and impression formation. Journal of Personality and Social Psychology, $88,816-826$.

Gaasholt, Ø \& Togeby, L. (1995). Interethnic Intolerance, Education, and Political Orientations: Evidence form Denmark. Political Behavior, 17: 265-285. 
Gerber, A. S., Huber, G. A., Doherty, D., \& Dowling, C. M. (2010). Personality and political attitudes: Relationships across issue domains and political contexts. American Political Science Review, 104, 111-133

Goldberg, L. R. (1992). The Development of Markers for the Big-Five Factor Structure. Psychological Assessment, 4: 26-42.

Goldberg, L. R. (1993). The Structure of Phenotypic Personality Traits. American Psychologist, 48: 26-34.

Gosling, S. D., Rentfrow, P. D. \& Swann Jr., W. B. (2003). A Very Brief Measure of the BigFive Personality Domains. Journal of Research in Personality, 37: 504-28.

John, Oliver P., Naumann, L. P., \& Soto, C. J. (2008). Paradigm Shift to the Integrative Big Five Trait Taxonomy: History, Measurement, and Conceptual Issues. In John, O. P., Robins, R. W. \& Pervin, L. A. (Eds.), Handbook of Personality Theory and Research. New York: Guilford Press, 114-58.

Hainmueller, J. \& Hiscox, M. J. (2010). Attitudes toward Highly Skilled and Low-skilled Immigration: Evidence from a Survey Experiment. American Political Science Review, 104: 61-84.

Jost, J.T., Federico, C.M. \& Napier, J.L. (2009). Political ideology: Its structure, functions, and elective affinities. Annual Review of Psychology, 60, 307-333.

McClosky, H. \& Brill, A. (1983). Dimensions of Tolerance: What Americans Believe About Civil Liberties. New York: Russell Sage Foundation.

McCrae, R. R., \& Costa, P. T., Jr. (1999). A five-factor theory of personality. In L. A. Pervin \& O. P. John (Eds.), Handbook of personality: Theory and research 2 nd ed., pp. 139 -153. New York: Guilford Pres

Mondak, J. J., \& Halperin, K. D. (2008). A Framework for the Study of Personality and Political Behavior. British Journal of Political Science, 38: 335-62.

Mondak, J. J. (2010). Personality and the Foundations of Political Behavior. New York: Cambridge University Press. 
Mondak, J. J., Hibbing, M. V., Canache, D., Seligson, M. A. \& Anderson, M. R. (2010a). Personality and Civic Engagement: An Integrative Framework for the Study of Trait Effects on Political Behavior. American Political Science Review, 104: 85-110.

Mondak, J. J., Canache, D., Seligson, M. A., \& Hibbing, M. V. (2010b). The Participatory personality: Evidence from Latin America. British Journal of Poltical Science, 41: 211-221.

Pratto, F., Sidanius, J., Stallworth, L. M., \& Malle, B. F. (1994). Social dominance orientation: A personality variable predicting social and political attitudes. Journal of Personality \& Social Psychology, 67: 741-76

Schuman, Howard, Bobo, L. \& Steeh, C. (1985). Racial Attitudes in America: Trends and Interpretations. Cambridge MA: Harvard University Press.

Sibley, C. G., \& Duckitt, J. (2008). Personality and prejudice: A meta-analysis and theoretical review. Personality and Social Psychology Review, 12: 248-27

Sides, J. and Citrin, J. (2007). European Attitudes toward Immigration: The Role of Interests, Identities, and Information. British Journal of Political Science, 37: 477-50

Sniderman, Paul M., Louk Hagendoorn, and Markus Prior (2004). Predisposing Factors and Situational Triggers: Exclusionary Reactions to Immigrant Minorities. American Political Science Review, 98: 35-50. 
Table 1: Vignette wording and response distribution in survey experiment

\begin{tabular}{llllll}
\hline "Denmark should allow more..." & Agree & $\begin{array}{l}\text { Agree } \\
\text { somewhat }\end{array}$ & $\begin{array}{l}\text { Disagree } \\
\text { somewhat }\end{array}$ & $\begin{array}{l}\text { Disagree } \\
\text { Numbers of } \\
\text { observations }\end{array}$ \\
\hline ... high-skilled immigrants from Western & 38.93 & 44.38 & 11.94 & 4.75 & 688 \\
countries to move to Denmark & $(278)$ & $(305)$ & $(77)$ & $(28)$ & \\
$\begin{array}{l}\text {... high-skilled immigrants from non-Western } \\
\text { countries to move to Denmark }\end{array}$ & 30.56 & 48.57 & 15.43 & 5.44 & 707 \\
$\ldots$ low-skilled immigrants from Western & $(227)$ & $(346)$ & $(102)$ & $(32)$ & \\
countries to move to Denmark & $(42)$ & 24.88 & 35.40 & 33.81 & 733 \\
.. low-skilled immigrants from non-Western & 5.17 & 23.13 & 37.43 & 34.27 & 756 \\
countries to move to Denmark & $(39)$ & $(182)$ & $(282)$ & $(253)$ & \\
\hline
\end{tabular}

Note: Cell entries in column 2-5 indicate weighted percentages with unweighted numbers of observations in parenthesis. "Don't know" answers are set to missing in the analysis. 
Table 2: Descriptive statistics for personality scales

\begin{tabular}{lcc}
\hline Personality trait & Scale mean (s.d.) & Chronbach's alpha \\
\hline Openness to Experience & $0.517(0.148)$ & 0.716 \\
Conscientiousness & $0.586(0.148)$ & 0.790 \\
Extraversion & $0.566(0.151)$ & 0.811 \\
Agreeableness & $0.560(0.152)$ & 0.737 \\
Neuroticism & $0.406(0.159)$ & 0.848 \\
\hline
\end{tabular}

Note: All scales are constructed to range between 0 (lowest observed value on trait) and 1 (highest observed value on trait). Number of observations $=2884$. 


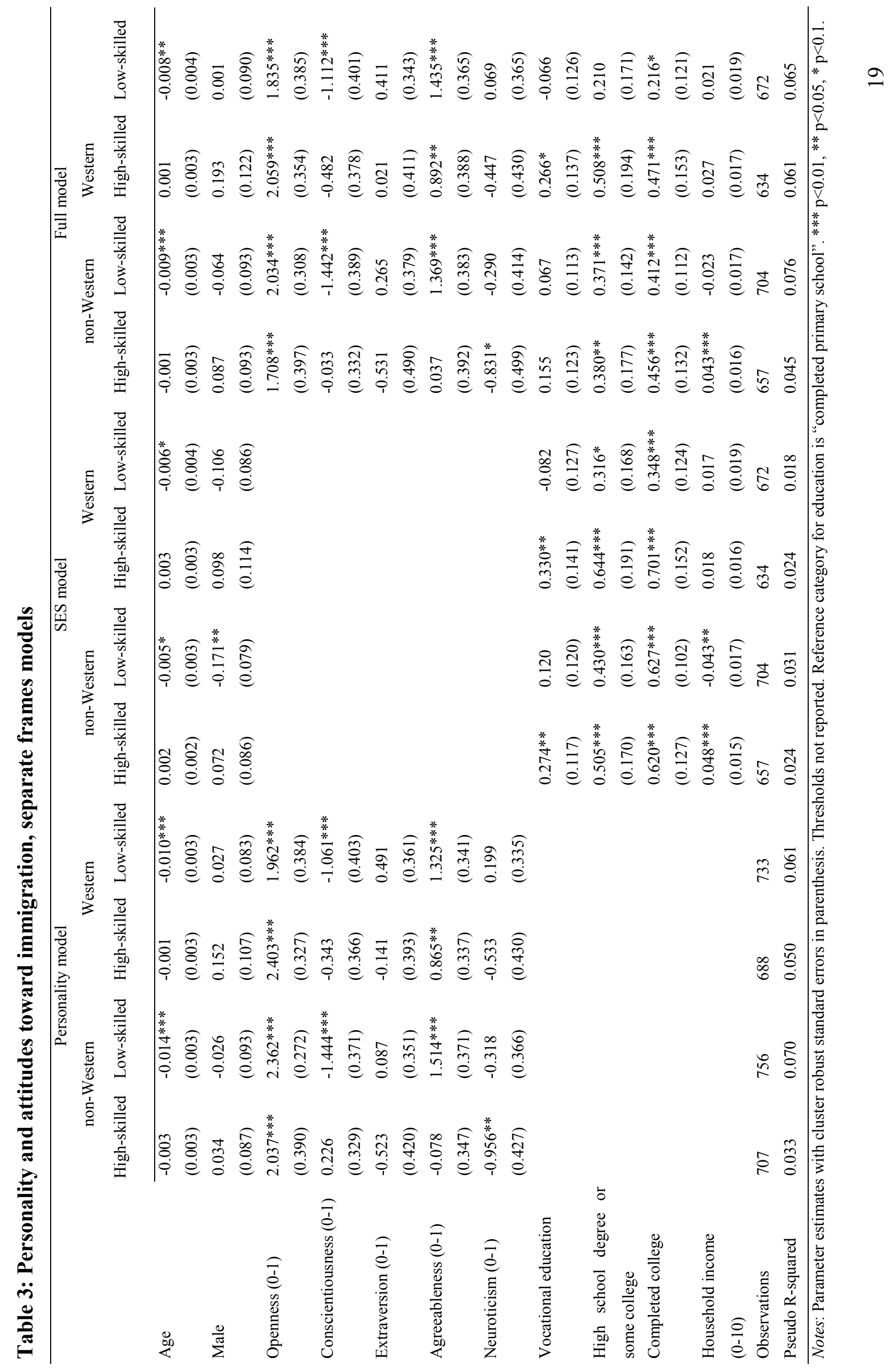


Table 4: Personality and attitudes toward immigration, collapsed frames models

\begin{tabular}{|c|c|c|c|c|}
\hline & $\begin{array}{l}\text { Personaliy } \\
\text { model }\end{array}$ & $\begin{array}{l}\text { SES } \\
\text { model }\end{array}$ & $\begin{array}{l}\text { Full } \\
\text { model }\end{array}$ & $\begin{array}{l}\text { Interaction } \\
\text { Model }\end{array}$ \\
\hline Age & $\begin{array}{l}-0.007 * * * \\
(0.002)\end{array}$ & $\begin{array}{l}-0.001 \\
(0.002)\end{array}$ & $\begin{array}{l}-0.004 * * \\
(0.002)\end{array}$ & $\begin{array}{l}-0.004 * * \\
(0.002)\end{array}$ \\
\hline Male & $\begin{array}{l}0.062 \\
(0.055)\end{array}$ & $\begin{array}{l}-0.024 \\
(0.047)\end{array}$ & $\begin{array}{l}0.067 \\
(0.054)\end{array}$ & $\begin{array}{l}0.063 \\
(0.054)\end{array}$ \\
\hline Openness $(0-1)$ & $\begin{array}{l}2.153 * * * \\
(0.207)\end{array}$ & & $\begin{array}{l}1.891 * * * \\
(0.210)\end{array}$ & $\begin{array}{l}1.890 * * * \\
(0.213)\end{array}$ \\
\hline Conscientiousness $(0-1)$ & $\begin{array}{l}-0.639 * * * \\
(0.204)\end{array}$ & & $\begin{array}{l}-0.727 * * * \\
(0.209)\end{array}$ & $\begin{array}{l}-1.276^{* * *} \\
(0.229)\end{array}$ \\
\hline Extraversion $(0-1)$ & $\begin{array}{l}-0.036 \\
(0.238)\end{array}$ & & $\begin{array}{l}0.009 \\
(0.245)\end{array}$ & $\begin{array}{l}0.025 \\
(0.238)\end{array}$ \\
\hline Agreeableness $(0-1)$ & $\begin{array}{l}0.968^{* * *} \\
(0.161)\end{array}$ & & $\begin{array}{l}1.004 * * * \\
(0.175)\end{array}$ & $\begin{array}{l}0.999 * * * \\
(0.174)\end{array}$ \\
\hline Neuroticism $(0-1)$ & $\begin{array}{l}-0.337 \\
(0.218)\end{array}$ & & $\begin{array}{l}-0.317 \\
(0.215)\end{array}$ & $\begin{array}{l}-0.318 \\
(0.217)\end{array}$ \\
\hline Vocational education & & $\begin{array}{l}0.159 * * * \\
(0.061)\end{array}$ & $\begin{array}{l}0.100 \\
(0.062)\end{array}$ & $\begin{array}{l}0.104 * \\
(0.062)\end{array}$ \\
\hline High school degree or some college & & $\begin{array}{l}0.459 * * * \\
(0.076)\end{array}$ & $\begin{array}{l}0.360 * * * \\
(0.081)\end{array}$ & $\begin{array}{l}0.357 * * * \\
(0.081)\end{array}$ \\
\hline Completed college & & $\begin{array}{l}0.560 * * * \\
(0.064)\end{array}$ & $\begin{array}{l}0.376^{* * *} \\
(0.062)\end{array}$ & $\begin{array}{l}0.379 * * * \\
(0.062)\end{array}$ \\
\hline Household income $(0-10)$ & & $\begin{array}{l}0.010 \\
(0.008)\end{array}$ & $\begin{array}{l}0.017 * * \\
(0.009)\end{array}$ & $\begin{array}{l}0.017 * * \\
(0.009)\end{array}$ \\
\hline High-skilled & $\begin{array}{l}1.314^{* * *} \\
(0.060)\end{array}$ & $\begin{array}{l}1.300 * * * \\
(0.056)\end{array}$ & $\begin{array}{l}1.360 * * * \\
(0.057)\end{array}$ & $\begin{array}{l}0.719 * * * \\
(0.203)\end{array}$ \\
\hline Western & $\begin{array}{l}0.032 \\
(0.065)\end{array}$ & $\begin{array}{l}0.050 \\
(0.067)\end{array}$ & $\begin{array}{l}0.051 \\
(0.067)\end{array}$ & $\begin{array}{l}0.053 \\
(0.067)\end{array}$ \\
\hline High-skilled x Western & $\begin{array}{l}0.184 * * \\
(0.075)\end{array}$ & $\begin{array}{l}0.130 \\
(0.079)\end{array}$ & $\begin{array}{l}0.159 * * \\
(0.078)\end{array}$ & $\begin{array}{l}0.158 * * \\
(0.078)\end{array}$ \\
\hline High-skilled x Conscientiousness & & & & $\begin{array}{l}1.097 * * * \\
(0.331)\end{array}$ \\
\hline Observations & 2,884 & 2,667 & 2,667 & 2,667 \\
\hline Pseudo R-squared & 0.158 & 0.140 & 0.169 & 0.171 \\
\hline
\end{tabular}


Figure 1: The conditional impact of Conscientiousness on attitudes toward immigration

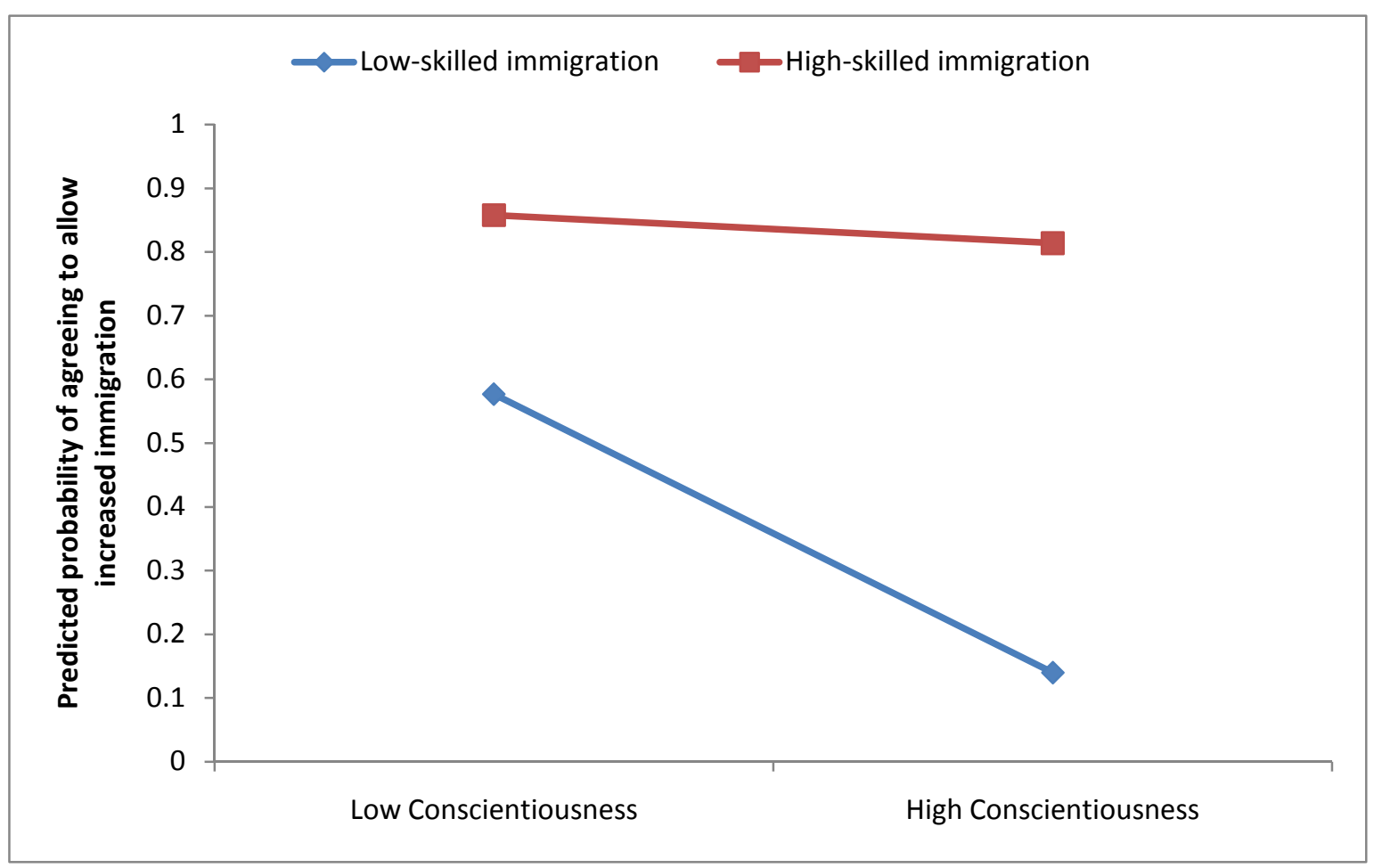

